\title{
Redistribution and labour supply
}

\author{
J orge Onrubia \\ Rafael Salas ${ }^{1}$ \\ J osé Félix Sanz \\ (Instituto de Estudios Fiscales and Universidad Complutense de Madrid)
}

(December, 2004)

\begin{abstract}
This paper explores the effect of personal income taxes on redistribution when labour supply reactions are taken into consideration. The results indicate that the classical non-behavioural results on redistribution are not necessarily satisfied in a more general behavioural framework. In this respect, it is shown that the relevant transition to measure redistribution is not the transition from the initial post-tax to the final post-tax income distribution, but rather from the more precise initial pre-tax to the final post-tax income distribution. In addition, the necessary and sufficient conditions to ensure redistribution in this wider setting are postulated, which helps determine the behavioural bias under alternative tax and labour supply models. This shows that the functional specification of labour supply may also affect the results.
\end{abstract}

JEL Classification: H31, H23, H24, D31 and D63

Key Words: Redistribution, inequality, personal income taxation and labour supply

\section{Acknowledgments:}

This paper has benefited from support by the European Communities TMR Network Living Standards, Inequality and Taxation [Contract \#ERBFMRXCT980248], the Spanish Ministry of Education under Project \#PB98-0546-C0202, the Spanish Ministry of Science and Technology \#SEC2003-08397 and \#BEC200301831, and Fundación BBVA. We acknowledge Peter J. Lambert and Miguel Ángel López-García for their valuable and detailed comments, which helped to improve this paper. We also thank Tony Shorrocks and International Workshop Income Redistribution and Welfare participants at the Università Bocconi at Milan, Italy, in May 2002, and the participants of the TMR Annual Meeting at the Universidad Carlos III in September 2001 for their comments and suggestions. The usual disclaimer applies.

\footnotetext{
1 Address for correspondence: Rafael Salas, Departamento de Análisis Económico I, Universidad Complutense de Madrid, Campus de Somosaguas, 28223 Madrid (Spain), Phone: 3491 3942512, Fax: 3491 3942561, E-mail: r.salas@ccee.ucm.es
} 


\section{Introduction}

This note explores the effect of taxes on redistribution when labour supply behavioural reactions are taken into account. In this respect, redistribution is measured in the classical way, defined in terms of the transition from pre-tax to post-tax income distributions. It is shown that non-behavioural (static) standard results on redistribution are not necessarily fulfilled in a more general behavioural (dynamic) framework. ${ }^{2}$ To this extent, correct redistribution analysis requires incorporation of behavioural effects induced by taxes. ${ }^{3}$

In this new setting, the paper distinguishes between three different income distributions:

(i) the initial pre-tax income distribution, which corresponds to gross incomes in the absence of taxes,

(ii) the initial post-tax income distribution, which is the gross income distribution once changes in labour supply have been taken into consideration as a result of tax change, and

(iii) the final post-tax income distribution, which reflects the distribution of initial posttax incomes net of taxes.

\footnotetext{
${ }^{2}$ The seminal contributions in the static literature include Fellman (1976), Jakobsson (1976) and Kakwani (1977). Extensions to personal income taxes with positive thresholds can be found in Keen et al. (2000). As far as the authors are aware, Preston's $(1987,1989)$ MPhil and PhD dissertations are the only references using a behavioural approach. Although some of the results in the current paper can be inferred from these analyses, the results presented are a step forward as we state them in terms of a key behavioural component, which helps to illustrate the main propositions.

${ }^{3}$ This is evidenced in an extensive empirical literature (see, for instance, Aaberge et al., 1995, 1999, 2000).
} 
In exploring redistribution, this conceptual distinction is theoretically relevant as it implies that net income and tax liability are determined endogenously. Within this framework, the relevant transition to measure redistribution is the one from the initial pre-tax to the final post-tax income distribution, and not the one from the initial post-tax to the final post-tax income distribution, as assumed in the non-behavioural setting.

In this wider context, the necessary and sufficient conditions to ensure redistribution are postulated. Moreover, standard Jakobsson-Fellman-Kakwani (JFK) results can be preserved under restricted conditions on the structure of the tax system and on the specification of the labour supply. As a result, it is found that labour supply specification does matter and it may influence the final redistributive impact of a given tax reform.

The structure of the paper is as follows. Section 2 defines the model and quantifies progressivity in terms of wage elasticities. Section 3 offers some applications to alternative tax structures and labour supply functions. The final section provides some concluding remarks.

\section{The model}

Assume a distribution of homogeneous individuals $i=1, \ldots, H$ with differences only in exogenous gross wage rates $\mathrm{W}=\left(w_{1}, \ldots, w_{H}\right)$. Assume the initial pre-tax income vector 
$\mathrm{Y}=\left(y_{1}, \ldots, y_{H}\right)$ generated by $y_{i}=w_{i} L_{i}$, where $L_{i}$ is the pre-tax labour supply and the distribution $\mathrm{Y}$ is confined to positive pre-tax income levels $y_{i} \in \mathbf{R}_{++} \equiv(0, \infty)$, as usual. ${ }^{4}$

\section{Labour supply}

Pre-tax labour supply adopts this general form $L_{i}=L\left(w_{i}, m_{i}\right)$, where $m_{i}$ is non-labour income, initially assumed to be zero, which allows for $\frac{\partial L}{\partial w}<0$. However, an upper bound $\eta_{L, w}=\frac{\partial L}{\partial w} \frac{w}{L} \geq-1$ needs to be satisfied. This weak restriction is consistent with standard Slutsky properties. Assume $\bar{L}$ to be the maximum labour supply as obtained for $\bar{w}$. This general form includes cases typical in the literature, including: the constant elasticity of substitution (CES) utility function (Stern, 1976 and Zabalza, 1983), where $\bar{w}$ tends to infinity, the elasticity of substitution is greater than one and $m_{i} \geq 0$; and the linear (Hausman, 1980, 1981) and log-linear (Burtless and Hausman, 1978) specifications. These specific functional forms are dealt with later. ${ }^{5}$ This labour supply specification is denoted $\mathrm{L}\left(\mathrm{w}_{\mathrm{i}}, \mathrm{m}_{\mathrm{i}}\right) \in L^{*}$.

\footnotetext{
${ }^{4}$ The basic model presented in this analysis assumes non-zero income values. However, most of the results can be extended for distributions with zero-income values $y_{i} \in \mathbf{R}_{+} \equiv[0, \infty)$.

${ }^{5}$ In the CES case, when the elasticity of substitution is lower than one, the condition $\eta_{L, w} \geq-1$ is satisfied for a range of the parameter values (see appendix B).
} 


\section{Tax structure}

The tax structure adopts the general form $T: \mathbf{R}_{+} \rightarrow \mathbf{R}$, such that $T(u)$ is continuous, increasing $\frac{\partial \mathbf{T}}{\partial \mathbf{u}}>0, \forall \mathbf{u}$ and differentiable on $\mathbf{u}$ and $\frac{\partial \mathbf{T}}{\partial \mathbf{u}}<1, \forall \mathbf{u}$. These are the standard assumptions in the literature. These tax structures belong to the class $\mathrm{T} \in T^{*}$. However, although this specification allows for negative taxation, as discussed later, it must satisfy certain conditions to be redistributive.

\section{Redistribution}

The primary aim of this paper is to generalize the standard results on redistribution of JFK. In doing so, the concept of local residual progression is employed. According to JFK, a necessary and sufficient condition for the existence of non-negative redistribution is that local residual progression is always lower than or equal to one (and greater than or equal to zero) for every pre-tax income distribution. When comparing two tax systems, the necessary and sufficient condition for non-lower redistribution is that the residual progression should be reduced (and non-negative).

To allow for labour supply effects, we distinguish between the initial post-tax income vector $\mathrm{Y}^{\prime} \in \mathbf{R}^{\mathbf{H}}{ }_{++}$, generated by $y_{i}^{\prime}=w_{i} L_{i}^{\prime}:{ }^{6}$

$$
L_{i}^{\prime}\left(w_{i}, m_{i}\right)=\left\{\begin{array}{cc}
L\left(w_{i}^{\prime}, m_{i}^{\prime}\right), & w^{\prime}<\bar{w} \\
\bar{L}, & w_{i}^{\prime} \geq \bar{w}
\end{array},\right.
$$

\footnotetext{
${ }^{6}$ Note that the initial post-tax income $Y^{\prime}$ corresponds to the actual taxable income.
} 
where $L_{i}^{\prime}$ is the post-tax labour supply, $w_{i}^{\prime}=w_{i}(1-t)$ is the marginal post-tax wage rate, and $m_{i}^{\prime}$ is the virtual non-wage income, and the final post-tax income vector $\mathrm{X}^{\prime} \in \mathbf{R}_{++}^{\mathbf{H}}$ is generated by $x_{i}^{\prime}=y_{i}^{\prime}-T\left(y_{i}{ }^{\prime}\right)$.

Within this setting, redistribution focuses on the transition from the initial pre-tax income distribution $(\mathrm{Y})$ to $\mathrm{X}^{\prime}$. The redistribution effect is consistently defined with the Lorenz curve criterion of second-order relative inequality dominance as proposed by Atkinson (1970).

\section{Definition 1}

A tax system is redistributive (progressive) if, and only if, for any initial pre-tax and final post-tax distributions, $\mathrm{Y}$ and $\mathrm{X}^{\prime} \in \mathbf{R}^{\mathbf{H}}{ }_{++}, \mathrm{X}^{\prime} \geq_{\mathrm{L}} \mathrm{Y}$. That is, if and only if, $\mathrm{X}^{\prime}$ weakly dominates Y:

$$
X^{\prime} \geq_{L} Y \quad \Leftrightarrow \sum_{i=1}^{k} \frac{x_{(i)}^{\prime}}{\mu\left(X^{\prime}\right)} \geq \sum_{i=1}^{k} \frac{y_{(i)}}{\mu(Y)} \quad, \forall k=1, \ldots, H,
$$

where $\mu\left(\mathrm{X}^{\prime}\right)$ and $\mu(\mathrm{Y})$ denote the mean of $\mathrm{X}^{\prime}$ and $\mathrm{Y}$, respectively. The terms $x_{(i)}^{\prime}$ and $y_{(i)}$ are the $i^{\text {th }}$ smallest elements of the corresponding distributions. 


\section{Definition 2}

Local residual progression, $\eta_{x^{\prime}, y}$, is defined as the elasticity of $x^{\prime}$ with respect to $y$, the relevant local redistribution measure in this setting. Conversely, the standard approach focuses on the residual progression defined as $\eta_{x^{\prime}, y^{\prime}}$. Note that, within this framework, $x^{\prime}(w)$ and $y(w)$ are positive non-decreasing functions on $w$. Then, $\eta_{x^{\prime}, y^{\prime}=\eta_{x^{\prime}, w}} \eta_{y^{\prime}, w}$.

Making use of these definitions, we state the following proposition, which is a natural extension of JFK:

\section{Proposition 1}

Given any initial pre-tax and final post-tax distributions $\mathrm{Y}$ and $\mathrm{X}^{\prime} \in \mathbf{R}^{\mathbf{H}}{ }_{++}$, generated by $\mathrm{T} \in T^{*}$ and $\mathrm{L}\left(\mathrm{w}_{\mathrm{i}}, \mathrm{m}_{\mathrm{i}}\right) \in L^{*}$, a necessary and sufficient condition for a tax system to be nonnegative redistributive (according to Lorenz second-order relative inequality dominance criterion) is:

$$
0 \leq \eta_{x^{\prime}, y} \leq 1 \text { for all } y \text {. }
$$

Proof: See appendix A.

\section{Proposition 2}

Given any initial pre-tax and final post-tax distributions $\mathrm{Y}$ and $\mathrm{X}^{\mathbf{\prime}} \in \mathbf{R}^{\mathbf{H}}{ }_{++}$, generated by $\mathrm{T} \in T^{*}$ and $\mathrm{L}\left(\mathrm{w}_{\mathrm{i}}, \mathrm{m}_{\mathrm{i}}\right) \in L^{*}$, a necessary and sufficient condition for a tax system to be non- 
negative redistributive (according to Lorenz second-order relative inequality dominance criterion) is:

$$
0 \leq \eta_{y^{\prime}, y} \eta_{x^{\prime}, y^{\prime}} \leq 1 \text { for all } y \text {. }
$$

Proof: It is derived from proposition 1 and taking into account the following decomposition $\eta_{x^{\prime}, y}=\eta_{y^{\prime}, y} \eta_{x^{\prime}, y^{\prime}}$

\section{Corollary 1}

JFK's condition $\left(0 \leq \eta_{x^{\prime}, y} \leq 1\right)$ becomes the relevant condition for non-negative redistribution when there is no labour supply reaction, such that $\eta_{y^{\prime}, y}=1$, which implies $\eta_{x^{\prime}, y}=\eta_{x^{\prime}, y^{\prime}}$.

It is worthwhile noting that $\eta_{y^{\prime}, y}$ is the key concept in this construction. This element captures labour supply changes, which we denote the behavioural (or dynamic) component. This new factor, not covered by the literature thus far, helps us understand and characterize the behavioural bias on redistribution because of the tax system, under alternative labour supply specifications. The importance of this term is summarized in Figure 1, which illustrates the role of this key element, $\eta_{y^{\prime}, y}$, in determining the overall redistributive effect. The static term is $\eta_{x^{\prime}, y^{\prime}}$, which captures the move from the Lorenz curve for $\mathrm{X}^{\prime}\left(\mathrm{L}_{\mathrm{x}^{\prime}}\right)$ to the Lorenz curve for $\mathrm{Y}^{\prime}\left(\mathrm{L}_{y^{\prime}}\right)$. Figure 1 depicts the case where $\eta_{x^{\prime}, y^{\prime}}<1$ (i.e., static positive redistribution as $\mathrm{L}_{\mathrm{x}^{\prime}}$ lies above $\mathrm{L}_{\mathrm{y}^{\prime}}$ ). However, this is not the whole picture because we are very interested in the total move from $\mathrm{L}_{\mathrm{y}}$ to $\mathrm{L}_{\mathrm{x}^{\prime}}$, captured by $\eta_{y^{\prime}, x}$. As shown in this case, the 
behavioural component, $\eta_{y^{\prime}, y}$, swaps the sign of the redistributive power of the tax. In other words, under a non-behavioural setting, the depicted tax appears to be redistributive, whereas, if we account for labour supply reactions ( $\eta_{y^{\prime}, y}$ different from one), it is negatively redistributive.

\section{FIGURE 1 ABOUT HERE}

Obviously, $\eta_{y^{\prime}, y}$ need not offset the static effect, but it certainly generates a specific behavioural bias. After some straightforward manipulations, this key concept $\eta_{y^{\prime}, y}$ can be expressed in terms of wage-income elasticities as:

$$
\eta_{y^{\prime}, y}=\frac{\eta_{y^{\prime}, w}}{\eta_{y, w}}
$$

Since $\eta_{y^{\prime}, w}=\eta_{L^{\prime}, w}+1$, it can be also written as a function of wage-labour supply elasticities:

$$
\eta_{y^{\prime}, y}=\frac{\eta_{L^{\prime}, w}+1}{\eta_{L, w}+1}
$$

Note that these elasticities are expressed in terms of the exogenous pre-tax wage rate as it identifies individuals. This can be extended to characterize redistribution for two alternative tax structures: 


\section{Proposition 3}

Given any initial pre-tax income distribution $Y \in \mathbf{R}^{\mathbf{H}}{ }_{++}$, assume two alternative taxes $\mathrm{T}^{\prime}$ and $\mathrm{T}^{\prime \prime} \in T^{*}$ that respectively generate two initial post-tax distributions $\mathrm{Y}^{\prime}$ and $\mathrm{Y}^{\prime \prime} \in \mathbf{R}^{\mathbf{H}}+$ and two final post-tax distributions $\mathrm{X}^{\prime}$ and $\mathrm{X}^{\prime \prime} \in \mathbf{R}_{++}^{\mathbf{H}}$ under a labour supply specification $\mathrm{L}\left(\mathrm{w}_{\mathrm{i}}, \mathrm{m}_{\mathrm{i}}\right) \in L^{*}$, then $\mathrm{T}^{\prime}$ is more redistributive than $\mathrm{T}^{\prime \prime}$ if, and only if, local residual progression from $\mathrm{Y}$ to $\mathrm{X}$ ' is not always greater than from $\mathrm{Y}$ to $\mathrm{X} "$ :

$$
0 \leq \eta_{x^{\prime}, y} \leq \eta_{x^{\prime \prime}, y} \text { for all } y
$$

which is equivalent to:

$$
0 \leq \eta_{y^{\prime}, y} \eta_{x^{\prime}, y^{\prime}} \leq \eta_{y^{\prime \prime}, y} \eta_{x^{\prime \prime}, y^{\prime \prime}} \text { for all } y
$$

Proof: See appendix A.

\section{Applications to alternative taxes and labour supply specifications}

In this section, the labour supply effects and $\eta_{y^{\prime}, y}$ for alternative taxes under different labour supply specifications are analysed. In general, we illustrate that the above condition for redistribution, $0 \leq \eta_{x^{\prime}, y} \leq 1$, is difficult to be satisfied, even in the simplest case. As an illustration, we first consider the case of a proportional tax, for which standard zeroredistribution is only guaranteed under certain conditions. Second, we examine linear progressive taxation applied to alternative labour supply specifications in order to search for conditions that guarantee positive redistribution. 


\subsection{Proportional tax case}

We see that, under very restricted conditions, a proportional tax achieves non-negative redistribution within our tax behavioural framework.

Initial pre-tax income $y_{i}$ is:

$$
y_{i}=\left\{\begin{array}{lc}
w_{i} L\left(w_{i}, 0\right), & 0 \leq w_{i} \leq \bar{w} \\
w_{i} \bar{L}, & w_{i} \geq \bar{w}
\end{array} .\right.
$$

Post-tax labour supply $\mathrm{L}_{\mathrm{i}}^{\prime}$ is:

$$
L_{i}^{\prime}=\left\{\begin{array}{ll}
L\left(w_{i}(1-t), 0\right), & 0 \leq w_{i}(1-t) \leq \bar{w} \\
\bar{L}, & w_{i}(1-t) \geq \bar{w}
\end{array} .\right.
$$

Initial post-tax income $y_{i}^{\prime}$ is:

$$
y_{i}^{\prime}=\left\{\begin{array}{lr}
w_{i} L\left(w_{i}(1-t), 0\right), & 0 \leq w_{i}(1-t) \leq \bar{w} \\
w_{i} \bar{L}, & w_{i}(1-t) \geq \bar{w}
\end{array} .\right.
$$

Final post-tax income $\mathrm{x}_{\mathrm{i}}$ is:

$$
x_{i}^{\prime}=\left\{\begin{array}{ll}
w_{i}(1-t) L\left(w_{i}(1-t), 0\right), & 0 \leq w_{i}(1-t) \leq \bar{w} \\
w_{i}(1-t) \bar{L} & w_{i}(1-t) \geq \bar{w}
\end{array} .\right.
$$


As $\eta_{x^{\prime}, y^{\prime}}=1$, the necessary and sufficient condition to guarantee redistribution neutrality $\mathrm{w}_{\mathrm{i}} \in$ $(0, \bar{w})$ is $\eta_{x^{\prime}, y}=\eta_{y^{\prime}, y}=1$. Hence, $\eta_{L^{\prime}, w}=\eta_{L, w}$. This stringent condition is satisfied in cases such as the log-linear labour supply specification and, when $m_{i}=0$, in the case of the CobbDouglas utility function (see below).

\subsection{A linear tax under different labour supply specifications}

Now we study the affine tax system as analysed by Atkinson and Stiglitz (1980), Atkinson (1995) and Hall and Rabushka (1995):

$$
T(y)=-Z+t y, Z \geq 0 \text { and } 1>t>0 .
$$

This tax scheme, which generates unambiguously $0 \leq \eta_{x^{\prime}, y^{\prime}} \leq 1$, is examined under three alternative functional forms: the CES, linear and log-linear specifications.

\subsubsection{CES}

The CES utility function is defined as:

$$
U(y, L)=y^{\rho}+\alpha(\bar{L}-L)^{\rho} \quad \alpha>0, \rho<1,
$$

from which the pre-tax labour supply $L$ can be recovered as:

$$
L\left(w_{i}, 0\right)=\frac{\bar{L}\left(w_{i} / \alpha\right)^{\sigma}}{w_{i}+\left(w_{i} / \alpha\right)^{\sigma}}, \quad w_{i} \geq 0,
$$


where $\bar{L}$ represents the maximum labour and $\sigma=1 /(1-\rho)$ is the elasticity of substitution.

Post-tax labour supply $L^{\prime}$ is:

$$
L^{\prime}\left(w_{i}, 0\right)=\frac{\bar{L}\left(w_{i}(1-t) / \alpha\right)^{\sigma}-Z}{w_{i}(1-t)+\left(w_{i}(1-t) / \alpha\right)^{\sigma}}, \quad 0 \leq w_{r}{ }^{\prime} \leq w_{i},
$$

where $w_{r}{ }^{\prime}$ is the post-tax reservation wage. Both labour supply functions are illustrated in Figure 2 for $\sigma>1$.

\section{FIGURE 2 ABOUT HERE}

It can be proved (see appendix B) that, for any $\alpha>0, \sigma>1$ (or $0<\rho<1$ ), $Z \geq 0$ and $1>t>0$, and $w_{i} \in\left(w_{r}{ }^{\prime}, \infty\right)$

$$
\eta_{L^{\prime}, w}>\eta_{L, w}>0
$$

So,

$$
\eta_{y^{\prime}, w}>\eta_{y, w}>1
$$

Hence,

$$
\eta_{y^{\prime}, y}>1
$$

Figure 3 illustrates this evidence. Positive redistribution is then not guaranteed. Note also that, under the proportional tax case, $Z=0$ and $t>0$, negative redistribution arises unless, in a 
Cobb-Douglas case, the parameter $\sigma$ converges to one. Consequently, under this CES specification, we generally find a regressivity behavioural bias due to $\eta_{y^{\prime}, y}>1$.

\section{FIGURE 3 ABOUT HERE}

3.2.2 The linear labour supply (Hausman, 1980, 1981)

Pre-tax labour supply $L$ is:

$$
L_{i}\left(w_{i}, 0\right)=\left\{\begin{array}{ll}
a w_{i}-b m_{i}+c, & 0 \leq w_{r} \leq w_{i} \leq \bar{w} \\
\bar{L}, & w_{i} \geq \bar{w}
\end{array},\right.
$$

where $a, b>0$. Again, assume $m_{i}=0$. In this case, $w_{r}=-c / a$, for $c \leq 0$ and $w_{r}=0$, for $c>0$.

Post-tax labour supply $L^{\prime}$ is:

$$
L_{i}^{\prime}\left(w_{i}, 0\right)=\left\{\begin{array}{ll}
c+a w_{i}(1-t)-b Z, & 0 \leq w_{r}{ }^{\prime} \leq w_{i} \leq \bar{w}^{\prime} \\
\bar{L}, & w_{i} \geq \bar{w}^{\prime}
\end{array},\right.
$$

where $w_{r}{ }^{\prime}=\frac{-c+b z}{a(1-t)}$ for $c-b Z \leq 0$ and $w_{r}{ }^{\prime}=0$, for $c-b Z>0$. So, $w_{r}{ }^{\prime} \geq w_{r}$ (strictly positive for $c$ -

$b Z<0$, and equals -to zero-, otherwise) and $\bar{w}=\frac{\bar{L}-c}{a}<\bar{w}^{\prime}=\frac{\bar{L}+b Z-c}{a(1-t)}$ for $Z \geq 0$ and $1>t>0$.

Note that

$$
\eta_{L, w}\left(w_{i}, 0\right)= \begin{cases}\frac{a w_{i}}{c+a w}, & w_{r}<w_{i} \leq \bar{w} \\ 0, & w_{i}>\bar{w}\end{cases}
$$

and 


$$
\eta_{L^{\prime}, w}\left(w_{i}, 0\right)=\left\{\begin{array}{lc}
\frac{a w_{i}(1-t)}{c-b Z+a w_{i}(1-t)}, & w_{r}{ }^{\prime}<w_{i} \leq \bar{w} \\
0, & w_{i}>\bar{w}^{\prime}
\end{array} .\right.
$$

Then, a negative redistributive (regressive) behavioural bias is generated for any a,b $>0$, $\mathrm{c} \leq 0, \mathrm{Z} \geq 0$ and $1>\mathrm{t}>0$, and $\mathrm{w}_{\mathrm{i}} \in\left(\mathrm{w}_{\mathrm{r}}{ }^{\prime}, \infty\right),{ }^{7,8}$

$$
\eta_{L^{\prime}, w} \geq \eta_{L, w} \geq 0
$$

So

$$
\eta_{y^{\prime}, y} \geq 1
$$

\section{FIGURE 4 AND 5 ABOUT HERE}

3.2.3 The iso-elastic labour supply specification (Burtless and Hausman 1978) Pre-tax labour supply $L$ is:

\footnotetext{
${ }^{7}$ If $c>0$ but not large enough such that $c<b Z / t$ is also satisfied.

${ }^{8}$ In the two examples so far, there is a restriction in the wage distributions to satisfy $w_{i}>w_{r}{ }^{\prime}$, (where $w_{r}{ }^{\prime}$ is the reservation wage after tax, below which labour supply is zero) and hence $Y^{\prime}, Y \in \mathbf{R}_{++}^{\mathbf{H}}$. However, the results on redistributions can be extended for $w_{i} \in[0, \infty)$ and therefore, to allow for zero income levels, $\mathrm{Y}^{\prime}, \mathrm{Y} \in \mathbf{R}^{\mathbf{H}}{ }_{+}$, in line with Keen et al. (2000), although here negative (increasing) taxes are allowed. In this case, $\eta_{L^{\prime}, w} \geq \eta_{L, w} \geq 0$ (and hence, $\eta_{y^{\prime}, y} \geq 1$ ), for all $w$, and $w_{r}{ }^{\prime} \geq w_{r}$ are conditions for $\mathrm{Y} \geq_{\mathrm{L}} \mathrm{Y}^{\prime}$. These conditions are satisfied in both examples.
} 


$$
L_{i}\left(w_{i}, m_{i}\right)=\left\{\begin{array}{l}
A w_{i}^{\alpha} m_{i}^{\beta}, \quad 0 \leq w_{i} \leq \bar{w} \\
\bar{L}, \quad w_{i} \geq \bar{w}
\end{array},\right.
$$

where $A, \alpha>0$ and $\beta \leq 0$ and $m_{i}>0$. Post-tax labour supply $L^{\prime}$ is:

$$
L_{i}^{\prime}\left(w_{i}, m_{i}\right)=\left\{\begin{array}{l}
A\left(w_{i}(1-t)\right)^{\alpha}\left(m_{i}+Z\right)^{\beta}, \quad 0 \leq w_{i} \leq \bar{w}^{\prime}, \\
\bar{L}, \quad w_{i} \geq \bar{w}^{\prime}
\end{array}\right.
$$

where $\bar{w}<\bar{w}^{\prime}$.

It can be proved that, for any $A, \alpha>0, \beta \leq 0, Z \geq 0$ and $1>\mathrm{t}>0$, and $\bar{w}>\mathrm{w}_{\mathrm{i}}>0$,

$$
\eta_{L^{\prime}, w}=\eta_{L, w}=\alpha
$$

So,

$$
\eta_{y^{\prime}, w}=\eta_{y, w}
$$

Hence,

$$
\eta_{y^{\prime}, y}=1
$$

Positive redistribution is produced for $\mathrm{Z}>0$ (between 0 and $\bar{w}$ ). Note also that zero redistribution arises under the proportional tax case $\mathrm{Z}=0$ and that negative redistribution is induced under $\mathrm{Z}<0$. Moreover, for any tax system, $\eta_{y^{\prime}, y}=1$ and so $\eta_{x^{\prime}, y}=\eta_{x^{\prime}, y^{\prime}}$ (between 0 and $\bar{w}$ ), which is the JFK result under no behavioural reactions to tax changes. This implies behavioural neutrality. Nonetheless, again we have a negative behavioural bias for $\mathrm{w}_{\mathrm{i}}$ $\in(0, \infty)$ and $\mathrm{Z} \geq 0$, as $\eta_{L^{\prime}, w} \geq \eta_{L, w} \geq 0$ and, therefore, $\eta_{y^{\prime}, y} \geq 1$ (see Figure 7). 


\section{FIGURE 6 AND 7 ABOUT HERE}

\section{Concluding remarks}

By making use of the concept of local residual progression, this paper decomposes redistribution into two components:

(i) progression due to the impact on labour supply behaviour induced by the tax change, captured by the transition from the initial pre-tax to the final post-tax income distribution;

(ii) progression as a consequence of the actual tax liability, quantified by the move from the initial to the final post-tax income distribution.

This decomposition allows a generalization of the standard JFK conditions on redistribution when labour supply reactions to taxes are taken into account. It also allows us to determine the behavioural bias, through the behavioural component $\eta_{y^{\prime}, y}$ isolated here, of applying a particular tax to a labour supply specification. In this richer framework, we find that the labour supply specification is relevant in evaluating the redistribution of taxation. Further research may explore extensions of the concept of redistribution to incorporate the notion of equality of opportunities. 


\section{References}

Aaberge, R., DAgsvik, J., StrøM, S., 1995. "Labor Supply Responses and Welfare Effects of Tax Reforms", Scandinavian Journal of Economics, 97, 635-659.

Aaberge, R., Colombino, U., Strøm, S., 1999. "Labor Supply in Italy: An Empirical Analysis of Joint Household Decisions, with Taxes and Quantity Constraints", Journal of Applied Econometrics, 14, 403-422.

Aaberge, R., Colombino, U., Strøm, S., 2000. "Labor Supply Responses and Welfare Effects from Replacing Current Tax Rules by a Flat Tax: Empirical Evidence from Italy, Norway and Sweden", Journal of Population Economics, 13, 595-621.

AtKInSON, A. B., 1970. "On the Measurement of Inequality", Journal of Economic Theory, 2, 244-263.

AtKinson, A. B., 1995. Public Economics in Action: Basic Income-Flat Tax Proposal, Clarendon Press, Oxford.

Atkinson, A. B., Stiglitz, J. E., 1980. Lectures on Public Economics, McGraw-Hill, Maidenhead, Berkshire, UK.

Burtless, G., Hausman, J. A., 1978. "The Effect of Taxation on Labour Supply: Evaluating the Gary Negative Income Tax Experiment", Journal of Political Economy, 86, 1103-1130.

Fellman, J., 1976. "The Effects of Transformations on Lorenz Curves, Econometrica, 44, 869-881.

Hall, R. E., RABuShKA, A., 1995. The Flat Tax, $2^{\text {nd }}$ ed., Hoover Institution Press, Stanford, CA.

Hausman, J. A., 1980. "The Effects on Wages, Taxes and Fixed Costs on Women's Labour Force Participation”, Journal of Public Economics, 14, 161-194.

Hausman, J. A. 1981, "Labour Supply", in H. J. Aaron and J. A. Pechman (eds.), How Taxes affect Economic Behaviour, 27-72, Brookings, Washington, DC.

Jakobsson, U., 1976. "On the Measurement of the Degree of Progression, Journal of Public Economics, 5, 161-168.

KAKWANI, N. C., 1977. "Applications of Lorenz Curves in Economic Analysis", Econometrica, 45, 719-727.

Keen, M., Papapanagos, H., Shorrocks, A., 2000. "Progressivity Effects of Structural Income Tax Reforms", Economic Journal, 100, 1-19. 
LAMBerT, P.J., 2001, The Distribution and Redistribution of Income, third edition, Manchester University Press, Manchester.

Preston, I. P., 1987. "The Redistributive Effect of Progressive Taxation, with Endogenous Labour Decisions", M Phil Thesis, Oxford University, unpublished.

Preston, I. P., 1989. “The Redistributive Effect of Progressive Taxation", DPhil Thesis, Oxford University, unpublished.

StERn, N. H., 1976. "On the Specification of Models of Optimum Income Taxation", Journal of Public Economics, 6, 123-162.

ZabalzA, A., 1983. "The CES Utility Function, Non-Linear Budget Constraints and Labour Supply. Results on Female Participation and Hours", Economic Journal, 93, 312-330. 
Figure 1

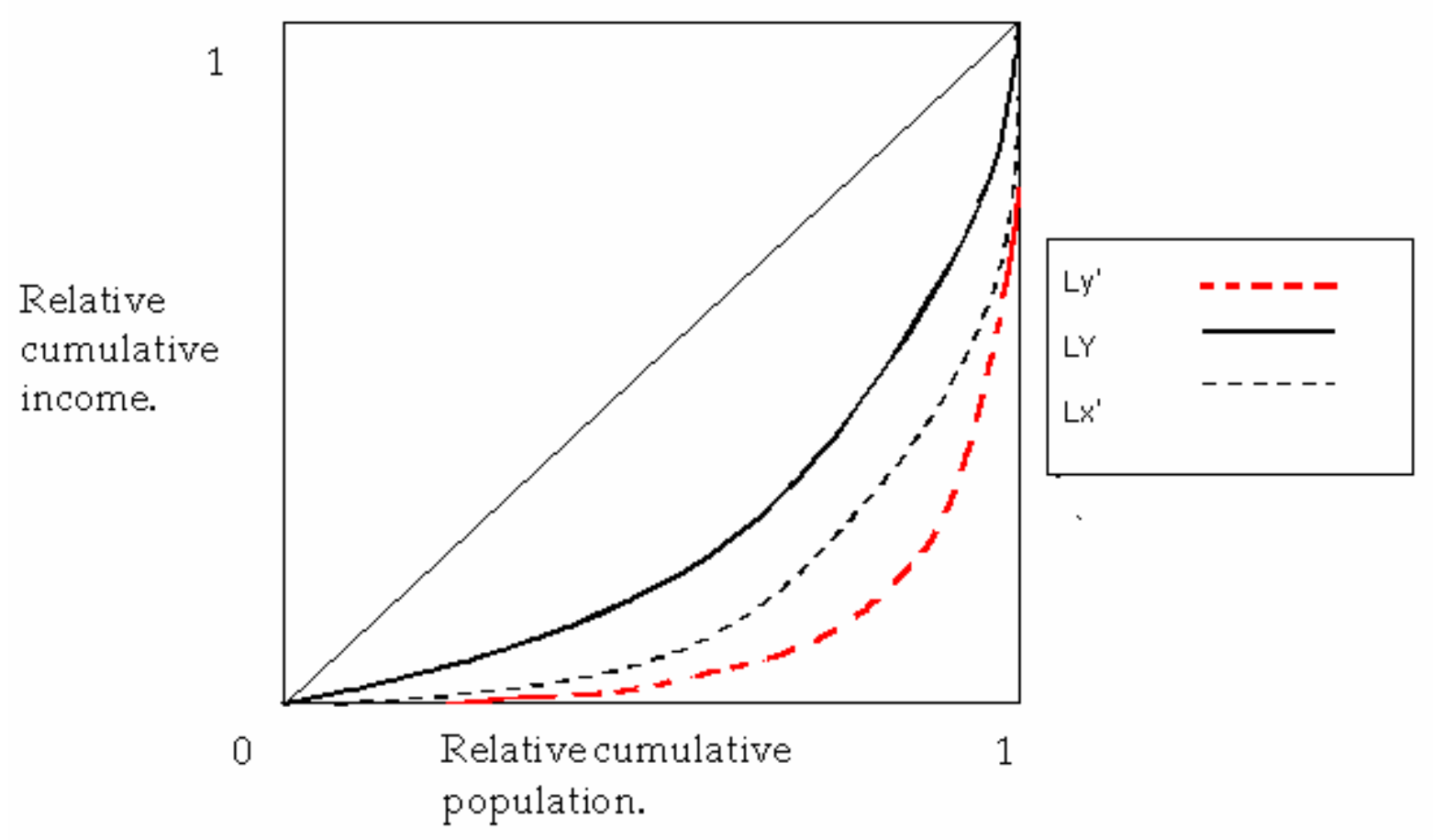


Figure 2

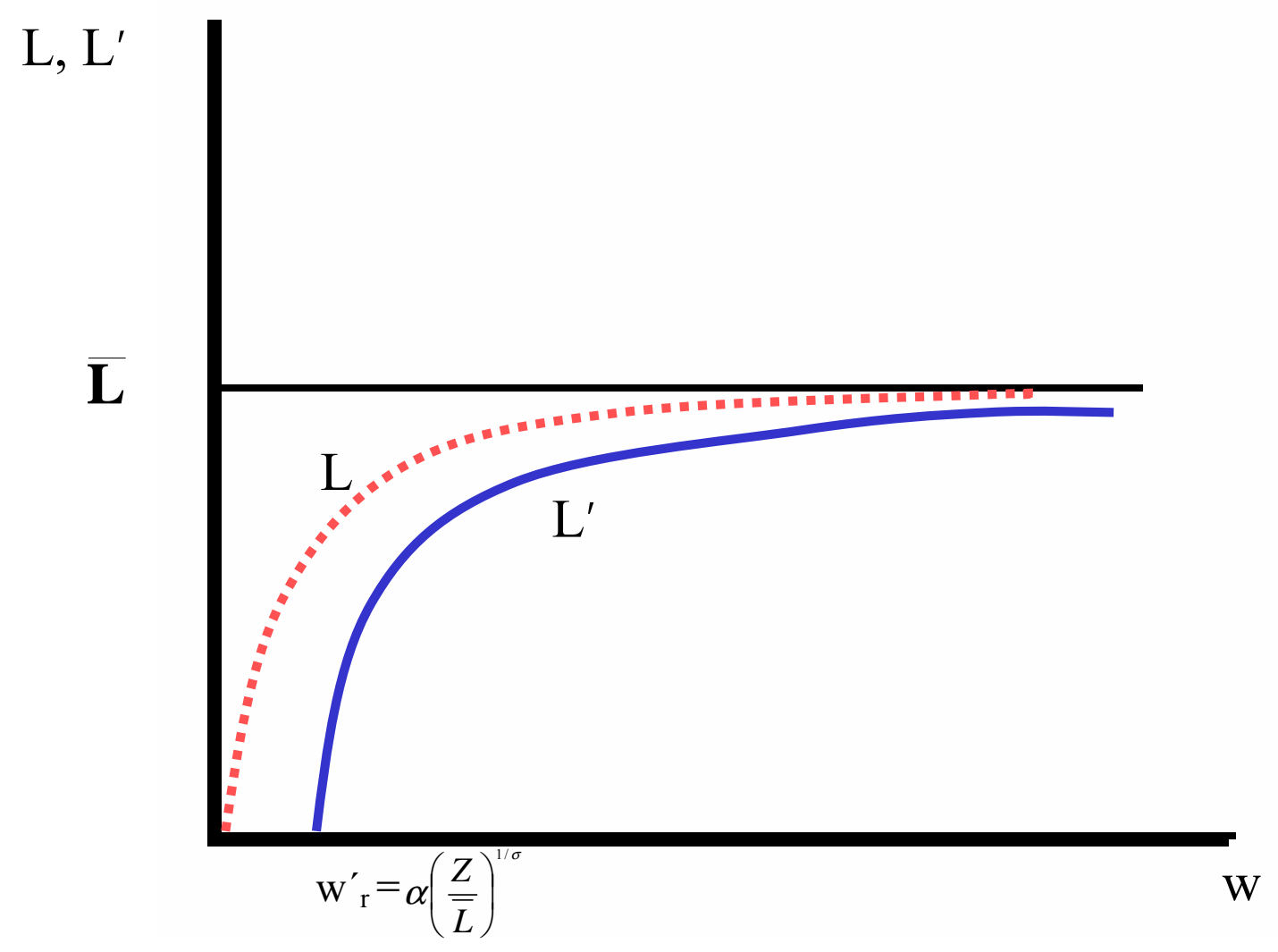


Figure 3

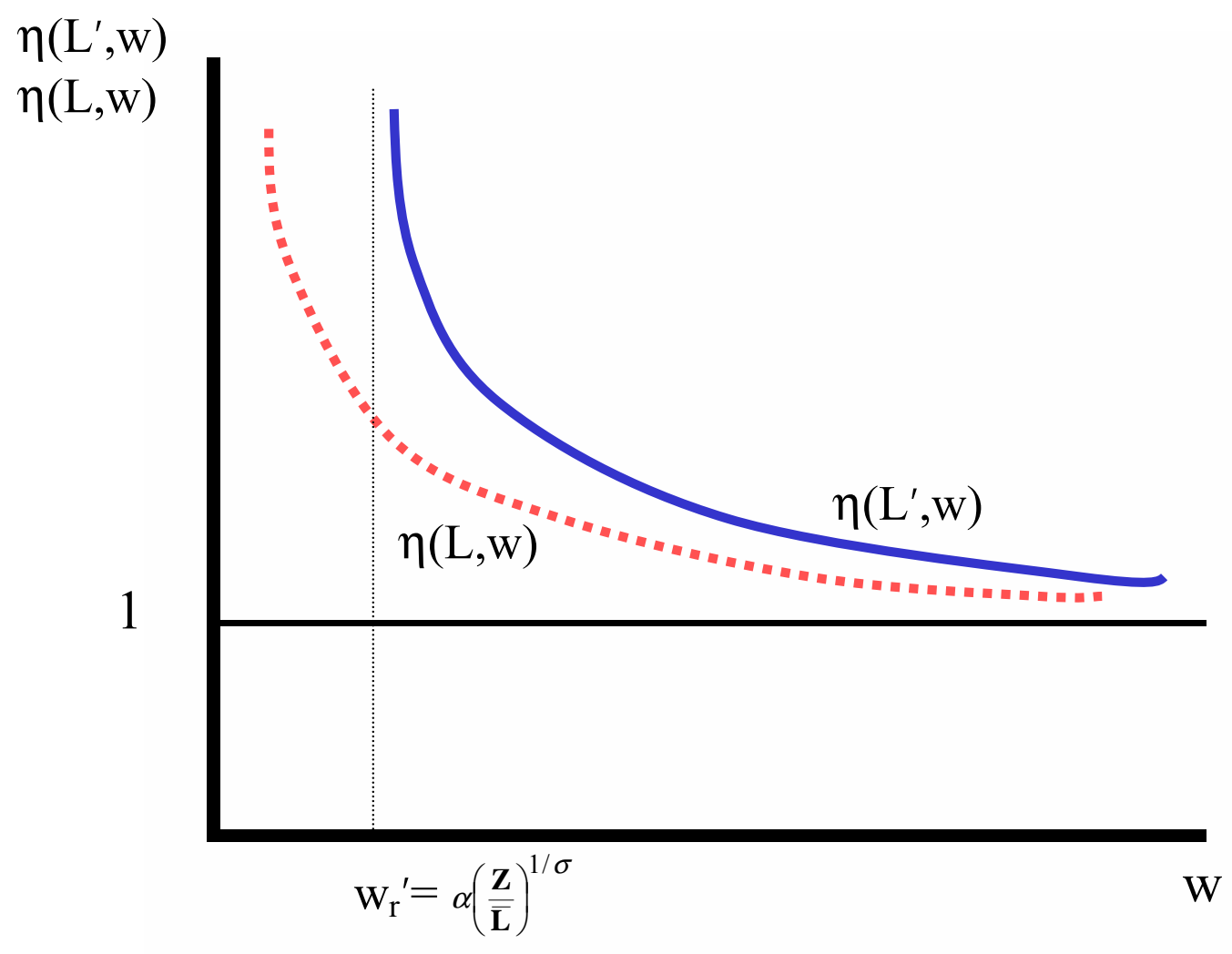


Figure 4

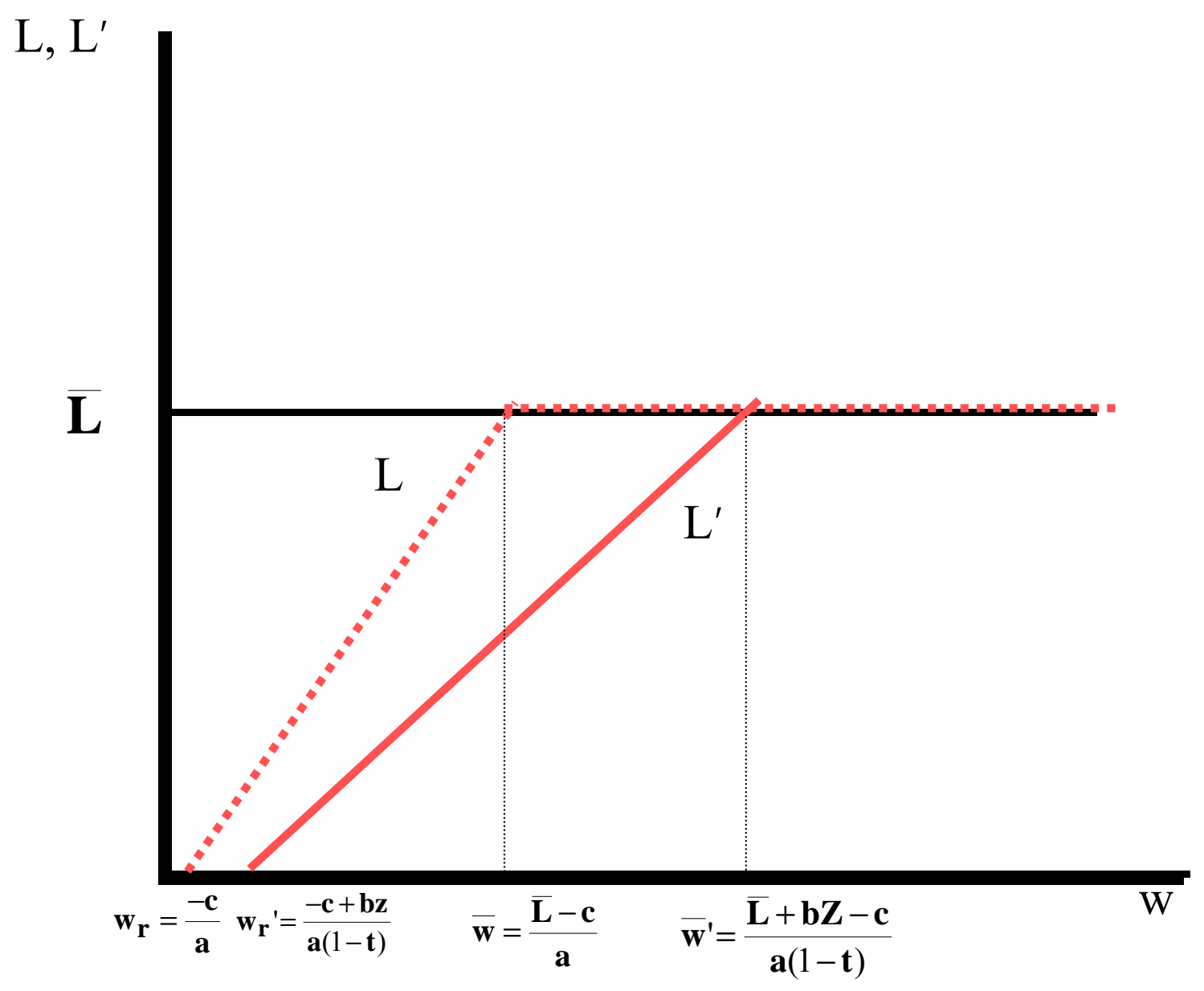


Figure 5

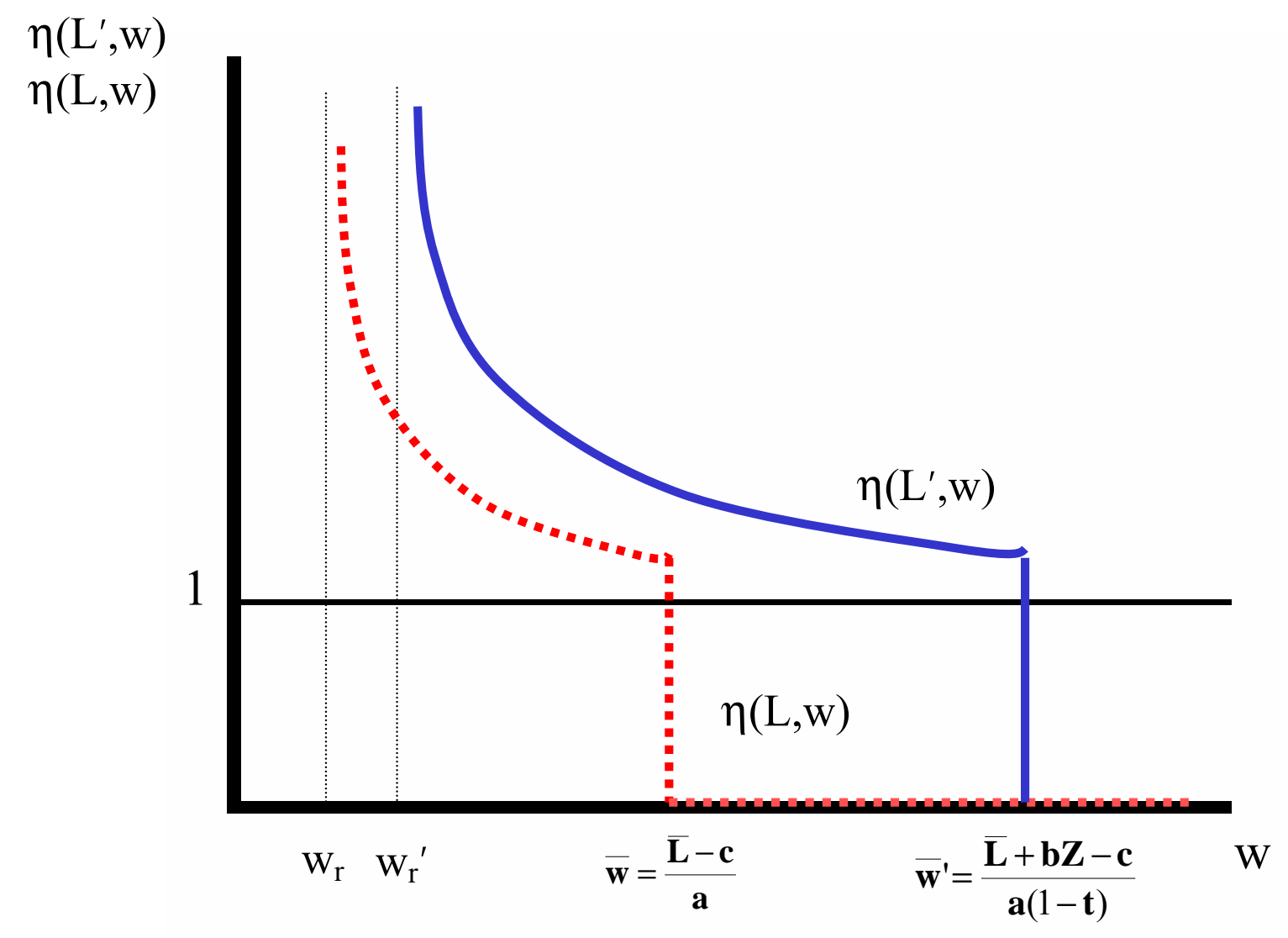


Figure 6

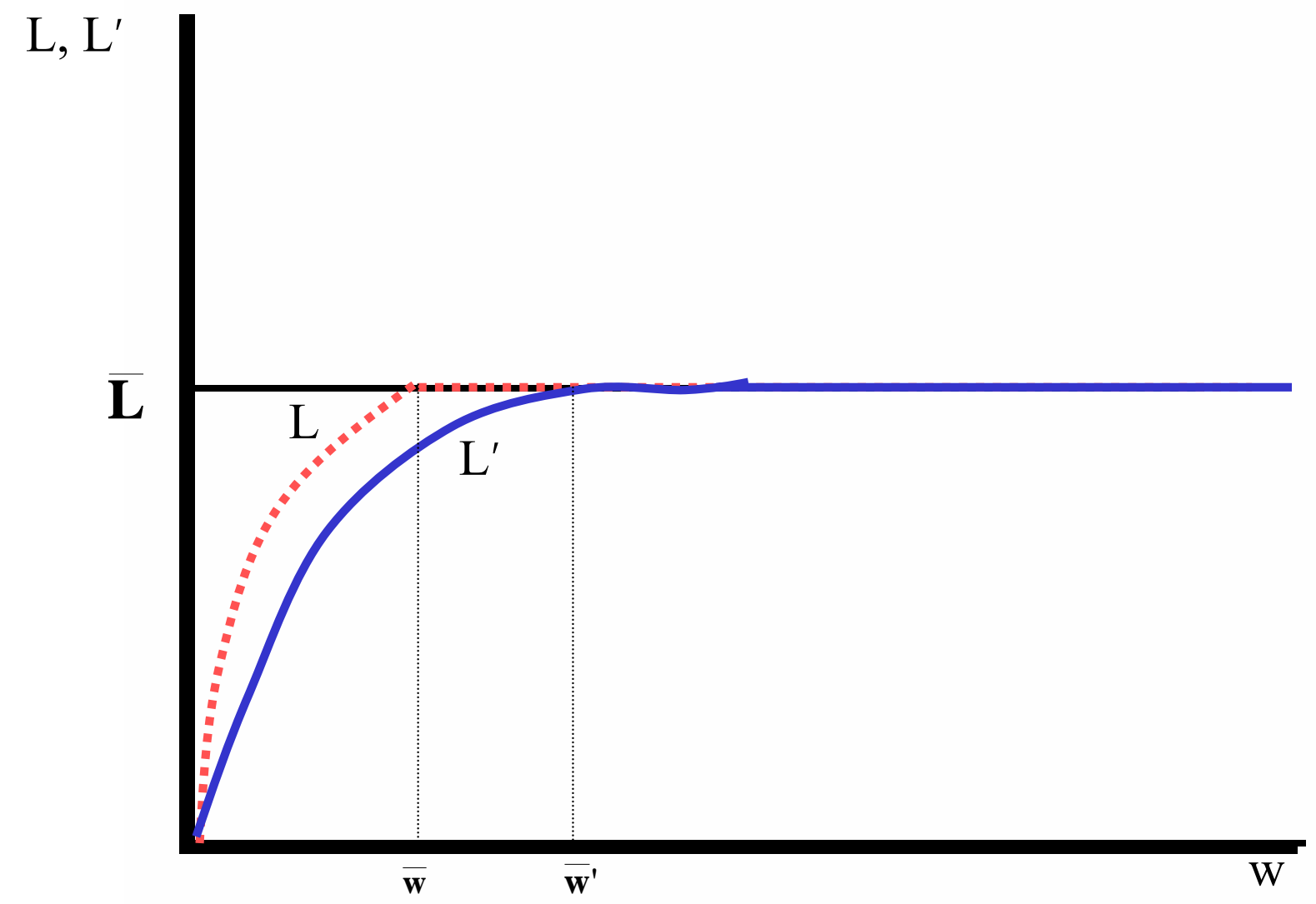


Figure 7

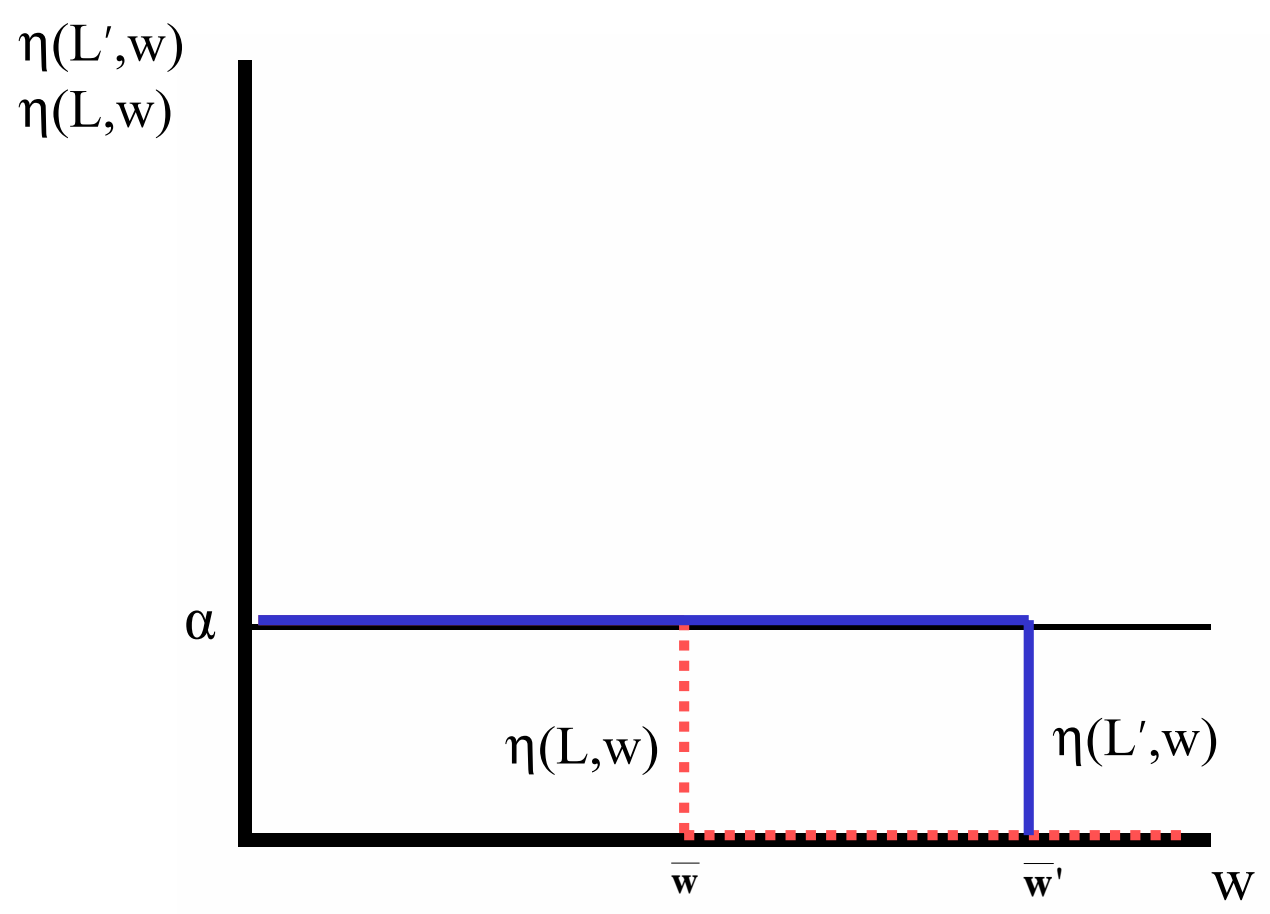




\section{Appendix A:}

\section{Proof of proposition 1:}

Given any initial pre-tax and final post-tax distributions $\mathrm{Y}$ and $\mathrm{X}^{\prime} \in \mathbf{R}^{\mathbf{H}}{ }_{++}$, generated by the tax and labour supply structures such as $\mathrm{T} \in T^{*}$ and $\mathrm{L}\left(\mathrm{w}_{\mathrm{i}}, \mathrm{m}_{\mathrm{i}}\right) \in L^{*}$, a necessary and sufficient condition for a tax system to be non-negative redistributive (according to Lorenz second-order relative inequality dominance criterion) is $0 \leq \eta_{x^{\prime}, y} \leq 1$ for all $y$.

In our context, with $\mathrm{T} \in T^{*}$ and $\mathrm{L}\left(\mathrm{w}_{\mathrm{i}}, \mathrm{m}_{\mathrm{i}}\right) \in L^{*}$, we can derive $\mathrm{x}^{\prime}(\mathrm{w})$ and $\mathrm{y}(\mathrm{w})$ as two nondecreasing positive functions of $w$, such that $x^{\prime}, y>0$ and $\eta_{x^{\prime}, w}, \eta_{y, w} \geq 0$. Given the restriction $\eta_{\mathrm{L}, \mathrm{w}}, \eta_{\mathrm{L}^{\prime}, \mathrm{w}} \geq-1$ for all $w$, and the expression $\eta_{x^{\prime}, y}=\frac{\eta_{x^{\prime}, w}}{\eta_{y, w}}=\frac{\eta_{x^{\prime}, w}}{\eta_{y^{\prime}, w}} \frac{\eta_{L^{\prime}, w}+1}{\eta_{L, w}+1}$, then $0 \leq \eta_{x^{\prime}, y} \leq 1$, for all $y$, is equivalent to $0 \leq \eta_{x^{\prime}, w} \leq \eta_{\mathrm{y}, \mathrm{w}}$ for all $w$. Consequently, we must prove that the latter condition is equivalent to $\mathrm{L}_{\mathrm{x}}(\mathrm{p}) \geq \mathrm{L}_{\mathrm{y}}(\mathrm{p})$ for all $\mathrm{p}$, for every initial distribution of $w{ }^{9}$

Proof: (based in Jackobsson proof)

The sufficient condition (the $\Rightarrow$ part). Given any ordered discrete initial wage distribution $\mathrm{W}=\left(\mathrm{w}_{0}, \mathrm{w}_{1}, \ldots, \mathrm{w}_{\mathrm{i}}, \ldots, \mathrm{w}_{\mathrm{n}}\right)$, the condition $0 \leq \eta_{\mathrm{x}^{\prime}, \mathrm{w}} \leq \eta_{\mathrm{y}, \mathrm{w}}$ for all $w$ implies

$$
\frac{x_{i}^{\prime}}{x_{i-1}^{\prime}} \leq \frac{y_{i}}{y_{i-1}} \text { for all } \mathrm{i}=2, \ldots, \mathrm{n}
$$

By the lemma due to Jackobsson (p. 164, 1976), then $L_{x^{\prime}}(p) \geq L_{y}(p)$ for all $p$.

The necessary condition (the $\Leftarrow$ part). If there exists an interval where $\eta_{\mathrm{x}^{\prime}, \mathrm{w}} \geq \eta_{\mathrm{y}, \mathrm{w}}$, then there always exists an initial distribution, within this interval, such that $L_{x^{\prime}}(p) \leq L_{y}(p)$ for all $\mathrm{p}$ that contradicts the result.

\footnotetext{
${ }^{9}$ It generalizes the Jackobsson-Kakwani result for any $\mathrm{x}^{\prime}(\mathrm{w})$ and $\mathrm{y}(\mathrm{w})$ functions of $w$ (and not only for afterand pre-tax income functions $\mathrm{x}^{\prime}$ and $\mathrm{y}^{\prime}$ of wage rates). It also modifies Lambert 8.6 theorem (p. 206, 2001), imposing Lorenz dominance (and not only concentration curves dominance) for non-decreasing functions.
} 


\section{Proof of proposition 3:}

Again, in our framework where $\mathrm{T} \in T^{*}$ and $\mathrm{L}\left(\mathrm{w}_{\mathrm{i}}, \mathrm{m}_{\mathrm{i}}\right) \in L^{*}$, the condition $0 \leq \eta_{x^{\prime}, y} \leq \eta_{x^{\prime \prime}, y}$ is equivalent to $0 \leq \eta_{\mathrm{x}^{\prime}, \mathrm{w}} \leq \eta_{\mathrm{x}, \mathrm{w}}$. Therefore, we have to prove the $0 \leq \eta_{x^{\prime}, w} \leq \eta_{x^{\prime \prime}, w}$ for all $w \Leftrightarrow$ $L_{x^{\prime}}(p) \geq L_{x^{\prime \prime}}(p)$ for all $p$, for every initial distribution of $w$.

\section{Proof:}

The sufficient condition (the $\Rightarrow$ part). Given any ordered discrete initial $\mathrm{w}=\left(\mathrm{w}_{0}, \mathrm{w}_{1}, \ldots, \mathrm{w}_{\mathrm{i}}, \ldots, \mathrm{w}_{\mathrm{n}}\right)$ distribution, $0 \leq \eta_{\mathrm{x}^{\prime}, \mathrm{w}} \leq \eta_{\mathrm{x}, \mathrm{w}}$ implies

$$
\frac{x_{i}^{\prime}}{x_{i-1}^{\prime}} \leq \frac{x^{\prime \prime}{ }_{i}}{x^{\prime \prime}{ }_{i-1}} \text { for all } \mathrm{i}=2, \ldots, \mathrm{n}
$$

By the lemma due to Jackobsson (p. 164, 1976), then $L_{x^{\prime}}(p) \geq L_{x^{\prime \prime}}(p)$ for all $p$.

The necessary condition is analogous as in proposition 1 . 


\section{Appendix B}

Given the labour supply for the CES specification when $m_{i}=0$ :

$$
L\left(w_{i}, 0\right)=\frac{\bar{L}\left(w_{i} / \alpha\right)^{\sigma}}{w_{i}+\left(w_{i} / \alpha\right)^{\sigma}}, \quad w_{i} \geq 0
$$

the wage elasticity is given by:

$$
\eta_{L, w}=\frac{\partial L}{\partial w_{i}} \frac{w_{i}}{L}=\frac{\bar{L}\left(\alpha^{\sigma} w_{i}^{\sigma}\right)(\sigma-1)}{\left(w_{i} \alpha^{\sigma}+w_{i}^{\sigma}\right)^{2}} \frac{w_{i}}{L}=\frac{(\sigma-1) w_{i}\left(\alpha^{2 \sigma} w_{i}+\alpha^{\sigma} w_{i}^{\sigma}\right)}{\left(w_{i} \alpha^{\sigma}+w_{i}^{\sigma}\right)^{2}}, \quad w_{i}>0
$$

which is positive for $\sigma>1$ and negative for $1>\sigma>0$. The wage derivative of the elasticity is always negative for $\alpha>0$

$$
\frac{\partial \eta_{L, w}}{\partial w_{i}}=-\frac{w_{i} \alpha^{\sigma}(\sigma-1)^{2}}{\left(w_{i} \alpha^{\sigma}+w_{i}{ }^{\sigma}\right)^{2}}, \quad w_{i}>0
$$

The limit of the wage elasticity as $w$ tends to infinity is

$$
\lim _{w \rightarrow \infty} \eta_{L, w}=(\sigma-1) \alpha^{\sigma}
$$

which tends to a positive number for $\sigma>1$ and to a negative number greater than -1 for the alternative case $1>\sigma>0$, whenever $(\sigma-1) \alpha^{\alpha}>-1$ (verified for all $0<\alpha \leq 1$ ).

After the affine tax, the labour supply is:

$$
L^{\prime}\left(w_{i}, 0\right)=\frac{\bar{L}\left(w_{i}(1-t) / \alpha\right)^{\sigma}-Z}{w_{i}(1-t)+\left(w_{i}(1-t) / \alpha\right)^{\sigma}}, \quad 0 \leq w_{r}{ }^{\prime} \leq w_{i}
$$

the wage elasticity is given by:

$$
\eta_{L^{\prime}, w}=\frac{\partial L^{\prime}}{\partial w_{i}} \frac{w_{i}}{L^{\prime}}=\frac{\bar{L} \alpha^{\sigma}\left(v_{i}{ }^{\sigma+1}(\sigma-1)+Z\left(\alpha^{2 \sigma} v_{i}+\alpha^{\sigma} v_{i}{ }^{\sigma}\right)\right.}{\left(v_{i} \alpha^{\sigma}+v_{i}{ }^{\sigma}\right)^{2}} \frac{v_{i}+\left(v_{i} / \alpha\right)}{\bar{L}\left(v_{i} / \alpha\right)^{\sigma}-Z}, \quad 0 \leq w_{r}{ }^{\prime}<w_{i}
$$

where $v_{i}=w_{i}(1-t)$. This wage elasticity is positive for $\sigma>1$ and $Z \geq 0$, given $\alpha>0$, in the relevant interval where $L^{\prime}>0$. We can infer that the derivative of the above elasticity with respect to $Z$ is always positive for $L^{\prime}>0$ as:

$$
\frac{\partial \eta_{L^{\prime}, w}}{\partial Z}=-\frac{\bar{L} \sigma\left(2 \alpha^{2 \sigma}\left(w_{i}(1-t)\right)^{2 \sigma+1}+\alpha^{\sigma}\left(w_{i}(1-t)\right)^{3 \sigma}+\alpha^{3 \sigma}\left(w_{i}(1-t)\right)^{\sigma+1}\right)}{\left(w_{i}(1-t) \alpha^{\sigma}+\left(w_{i}(1-t)\right)^{\sigma}\right)^{2}\left(\bar{L}\left(w_{i}(1-t)\right)^{\sigma}-Z \alpha^{\sigma}\right)^{2}}, \quad 0 \leq w_{r^{\prime}}{ }^{\prime}<w_{i} .
$$


We must prove that:

$$
\eta_{L^{\prime}, w}>\eta_{L, w}>0 \quad 0 \leq w_{r}{ }^{\prime}<w_{i}
$$

for $\alpha>0, \sigma>1, Z \geq 0$, and $1>t>0$.

That is:

$$
\frac{\bar{L} \alpha^{\sigma}\left(v_{i}{ }^{\sigma+1}(\sigma-1)+Z\left(\alpha^{2 \sigma} v_{i}+\alpha^{\sigma} v_{i}{ }^{\sigma}\right)\right.}{\left(v_{i} \alpha^{\sigma}+v_{i}{ }^{\sigma}\right)^{2}} \frac{v_{i}+\left(v_{i} / \alpha\right)^{\sigma}}{\bar{L}\left(v_{i} / \alpha\right)^{\sigma}-Z}>\frac{(\sigma-1) w_{i}\left(\alpha^{2 \sigma} w_{i}+\alpha^{\sigma} w_{i}{ }^{\sigma}\right)}{\left(w_{i} \alpha^{\sigma}+w_{i}{ }^{\sigma}\right)^{2}}, \quad 0 \leq w_{r}{ }^{\prime}<w_{i}
$$

where $v_{i}=w_{i}(1-t)$. Given $Z \geq 0$ :

$$
\frac{\bar{L} \alpha^{\sigma}\left(v_{i}{ }^{\sigma+1}(\sigma-1)+Z\left(\alpha^{2 \sigma} v_{i}+\alpha^{\sigma} v_{i}{ }^{\sigma}\right)\right.}{\left(v_{i} \alpha^{\sigma}+v_{i}{ }^{\sigma}\right)^{2}} \frac{v_{i}+\left(v_{i} / \alpha\right)^{\sigma}}{\bar{L}\left(v_{i} / \alpha\right)^{\sigma}-Z} \geq \frac{(\sigma-1) v_{i}\left(\alpha^{2 \sigma} v_{i}+\alpha^{\sigma} v_{i}{ }^{\sigma}\right)}{\left(v_{i} \alpha^{\sigma}+v_{i}{ }^{\sigma}\right)^{2}}, \quad 0 \leq w_{r}{ }^{\prime}<w_{i}
$$

because

$\frac{\partial \eta_{L^{\prime}, w}}{\partial Z}>0$

We also have, given $t>0$ :

$$
\frac{(\sigma-1) v_{i}\left(\alpha^{2 \sigma} v_{i}+\alpha^{\sigma} v_{i} \sigma\right)}{\left(v_{i} \alpha^{\sigma}+v_{i}{ }^{\sigma}\right)^{2}}>\frac{(\sigma-1) w_{i}\left(\alpha^{2 \sigma} w_{i}+\alpha^{\sigma} w_{i}{ }^{\sigma}\right)}{\left(w_{i} \alpha^{\sigma}+w_{i}{ }^{2}\right)^{2}}, \quad 0<w_{i}
$$

because

$\frac{\partial \eta_{L, w}}{\partial w}<0$

Transitivity completes the result.

This result is also true for all $1>\sigma>0$, involving $\frac{\partial L}{\partial w}<0$, and not only for $\sigma>1$ (for all $0<\alpha \leq 1)$. Note that, in this case, $\eta_{L^{\prime}, w}>\eta_{L, w}>-1$ for $\mathrm{w}_{\mathrm{i}}>0$.

Finally, in the Cobb-Douglas case, when $\sigma=1$ behavioural neutrality is reached, whenever $\mathrm{Z}=0$ as $\eta_{L^{\prime}, w}=\eta_{L, w}=0$ for $\mathrm{w}_{\mathrm{i}}>0$. 